Article

\title{
The Effects of Maturity of Project Portfolio Management and Business Alignment on PMO Efficiency
}

\author{
Joong Hoon Ko ${ }^{1}$ (D) and Daecheol Kim ${ }^{2, * \mathbb{D}}$ \\ 1 Department of Business Administration, Hanyang University, Seoul 04763, Korea; \\ mazeltov4u@hanyang.ac.kr \\ 2 School of Business, Hanyang University, Seoul 04763, Korea \\ * Correspondence: dckim@hanyang.ac.kr; Tel.: +82-2-2220-1043
}

Received: 22 November 2018; Accepted: 30 December 2018; Published: 5 January 2019

check for updates

\begin{abstract}
The purpose of this research is to analyze efficiencies of project management offices (PMOs) using the data envelopment analysis (DEA). As the post-analysis of the efficiency analysis, the causal factors affecting the efficiencies of PMOs were tested. 87 PMOs were used to analyze their efficiencies. In the constant returns-to-scale model, 11 PMOs were completely efficient and 76 PMOs were inefficient. In the variable returns-to-scale (VRS) model, 26 PMOs were efficient and 61 PMOs were inefficient. The efficiency analysis by the DEA has the advantage of deriving the scale efficiency for each DMU. From the result of the post-analysis, it was found that the PMO efficiency was positively influenced by the project portfolio management maturity (PPMM) and the degree of strategic alignments with the business goals. In conclusion, by improving PPMM and strengthening the strategic alignments with business goals, higher efficiency and performance of the PMO can be expected.
\end{abstract}

Keywords: efficiency; data envelopment analysis; PMO; PPMM; business alignment

\section{Introduction}

From the mid-1990s, one of the notable changes in project management is in the growth of project management office (PMO). As an example, according to the survey by the PM Solutions, Inc., 47 percent of respondents answered that they established PMOs in 2000. The figure increased to 77 percent in 2006 and 87 percent in 2012. In line with this trend, many Korean companies are also increasingly implementing PMOs. Since 2014, even public institutions have been showing interest in PMOs. One of the reasons for the popularity of PMOs is the increase in the importance of project portfolio management (PPM). This is because PMOs are required to manage project portfolios from a central organization across the enterprise. The PPM is an approach to maximize accomplishments of projects in a portfolio by identifying, prioritizing, and analyzing the potential value from a set of projects and programs [1].

Thus, the main purpose of their attempt to implement PMOs is to improve performances of projects such as return on investment, cost reduction, and project success rates. However, according to the report released by the PM Solutions [2], only 33 percent of all respondents who have implemented PMO have experienced improvements in completing projects within the budget and with productivity, or in project success rates. In other words, many PMOs still fail to deliver their own value in project management. Since the global financial crisis in 2008, the global economy has grown slowly with an average annual growth rate of $3.5 \%$ even if the economic growth rate of some countries with large populations, such as China and India, exceeds 6\% [3]. Therefore, the competition is getting more intense, and efficiency management is getting more important in corporate sustainability [4]. 
As the business environment changes drastically, most of the tasks carried out have characteristics of a project that are not repetitive, but new and unique tasks $[5,6]$. Therefore, the success or failure of these projects has a profound effect on the performance of the company. Accordingly, a systematic process for the limited allocation of resources to the increased projects has become necessary. Therefore, many companies have been trying to implement PPMs and PMOs. However, their performances were not all satisfactory. One of the reasons for this different result is the difference in their project portfolio management maturity (PPMM). Project management maturity has a positive effect on the project performance [7], and the continual improvement of the project management performance can be achieved through the improvement of project management maturity [8]. Likewise, a PPMM might also affect the performance of the PPM and in turn PMO. The PPM is an effective approach to rapidly identify and decide which projects or programs they should select and conduct to enhance their organization's ability to support enterprise goals and deliver value [9]. As the PPMM of a company increases, so does the ability of a company to achieve its goals, which can eventually lead to higher PMO performance. Therefore, the PPMM might have a significant impact on the performance of the PMOs, and their performances may also be different depending on the PPMM. However, there are few studies on the impact of the PPMM on PMO.

Besides, a project portfolio must be cohesive, directed to the goals of the company, and have a clarity of purpose to work efficiently and create value. Thus, the strategic alignment of a project portfolio with the business goals of the organization is the key to deliver the PPM's and PMO's value [10]. For example, PMOs with their project portfolios aligned with strategic objectives performed almost twice as much as PMOs without it in terms of implementing successful strategies and creating significant value [11]. Moreover, these aligned PMOs achieved four times higher performance in terms of executing a planned strategy and three times more in terms of success than the PMOs without alignments [11]. From the perspective of achieving high performance with limited resources, the strategic alignment with their business goals seems to be closely related to the efficiency. Therefore, it is a key factor considered in the efficiency analysis of the PMOs. Even though the efficiency is very important in terms of corporate sustainability [4], there are few studies on the efficiency analysis of PMOs.

Despite the increasing importance of PMOs, there are few empirical studies on why PMO outcomes are unsatisfactory or different between organizations. In addition, there are few studies that have demonstrated program or portfolio maturity and business alignment as the causes of PMO efficiency difference between organizations. On the other hand, as the importance of the project increases in the enterprise, the possibility that the project benefit management directly affects the benefit of the enterprise has increased. In other words, it has not been studied whether the benefit management for an individual project affects corporate benefits and how these effects are related to PMO efficiency.

Therefore, this study on the efficiency analysis of PMOs has very important meaning. To empirically prove the impact of PPMM and alignment of portfolio with business goals on the PMO efficiency, two research questions are proposed: Does the PPMM have a significant effect on the efficiency of the PMO? Does the strategic alignment with business goals have a significant effect on the efficiency of the PMO? To obtain the PMO efficiency score, data envelopment analysis (DEA) is used. The improvement directions are also provided for the inefficient PMOs to benchmark the efficient PMOs. Besides, companies can improve their PMO efficiency by improving the PPMM and strengthening strategic alignments with their business goals.

\section{Key Literature Reviews}

\subsection{Data Envelopment Analysis (DEA) and Project Efficiency}

The data envelopment analysis (DEA), developed by Charnes et al. [12], derives the efficiency frontier by simultaneously considering multiple input and output factors. Then, it measures the 
efficiency of a DMU compared with other DMUs [13-15]. The DMUs represent the organizational units to be evaluated, such as public institutions, schools, hospitals, and so on. In this study, PMOs correspond to decision-making units [16]. The DEA has various models according to the purposes of studies. The CCR (Charnes, Cooper, and Rhodes) model and the BCC (Banker, Charnes, and Cooper) model are representative [12,17]. The CCR model is also called as the CRS model because it assumes constant returns to scale. Meanwhile, the BCC model is also called as the VRS model because it assumes variable returns to scale $[16,18]$. In the DEA, according to the characteristics of the DMUs to be analyzed and the purpose of the analysis, the CCR model and the BCC model are classified into the input-oriented model and the output-oriented model. In general, the efficiency in input-oriented model can be improved by reducing the input value while keeping the output values constant. Meanwhile, in the case of output-oriented model, the efficiency can be enhanced as the output value increases while the input values remain constant [16]. Let us assume that the number of DMUs is K and, for each $D M U_{k}(k=1,2,3, \ldots, K)$, there are $\mathrm{M}$ input factors $x_{m}(m=1,2,3, \ldots, M)$ and $\mathrm{N}$ output factors $y_{n}(n=1,2,3, \ldots, N)$. Then, the efficiency of kth DMU can be obtained through the below output-oriented CCR and BCC models.

The output-oriented CCR model can be solved as follows.

$$
\begin{aligned}
& \phi^{k^{*}}=\max _{\theta, i} \phi^{k} \\
& \text { subject to } \\
& x_{m}^{k} \geq \sum_{k=1}^{K} x_{m}^{k} \lambda^{k}, m=1,2,3, \ldots, M ; \\
& \phi^{k} y_{n}^{k} \leq \sum_{k=1}^{K} y_{n}^{k} \lambda^{k}, n=1,2,3, \ldots, N ; \\
& \lambda^{k} \geq 0, k=1,2,3, \ldots, K
\end{aligned}
$$

The following output-oriented BCC model has a constraint of the sum of $\lambda$ in (1) to have a convexity constraint.

$$
\begin{aligned}
& \phi^{k^{*}}=\max _{\theta, i} \phi^{k} \\
& \text { subject to } \\
& x_{m}^{k} \geq \sum_{k=1}^{K} x_{m}^{k} \lambda^{k}, m=1,2,3, \ldots, M ; \\
& \phi^{k} y_{n}^{k} \leq \sum_{k=1}^{K} y_{n}^{k} \lambda^{k}, n=1,2,3, \ldots, N ; \\
& \sum_{k=1}^{K} \lambda^{k}=1 ; \\
& \lambda^{k} \geq 0, k=1,2,3, \ldots, K
\end{aligned}
$$

The scale efficiency (SE) can be obtained by dividing the efficiency value obtained from the CCR model by that of the BCC model. If the scale efficiency of $k^{\text {th }}$ DMU equals to 1 , it means that it is efficient in scale, and if less than 1 , it is considered as inefficient in scale. In cases where a DMU is not efficient from the scale point of view, the state of scale economy can be identified [16,19].

Since traditional DEA has a deterministic nature and is unable to account for measurement errors and variable fluctuation, we take into the bootstrap procedure proposed by Simar and Wilson [20] as follows.

Step 1. Compute $\hat{\theta}_{i}$ for all DMUs $i=1, \ldots, N$ using DEA.

Step 2. Use those $M(M<N)$ DMUs, for which $\hat{\theta}_{i}>1$ holds, in a truncated regression (left-truncation at 1$)$ of $\hat{\theta}_{i}$ on $z_{i}$ to obtain coefficient estimates $\hat{\beta}$ and an estimate for variance parameter $\hat{\sigma}$ by maximum likelihood.

Step 3. Loop over the following Steps 3.1-3.4 $K$ times, in order to obtain sets of $K$ bootstrap estimates $\hat{\theta}_{i}^{k}$ for each DMU $i=1, \ldots, N$, with $k=1, \ldots, K$. 
3.1 For each DMU $i=1, \ldots, N$, draw an artificial error $\widetilde{\varepsilon_{i}}$ from the truncated $N(0, \hat{\sigma})$ distribution with left-truncation at $1-z_{i} \hat{\beta}$.

3.2 Calculate artificial efficiency scores $\widetilde{\theta_{i}}$ as $z_{i} \hat{\beta}+\widetilde{\varepsilon_{i}}$ for each DMU $i=1, \ldots, N$.

3.3 Generate $i=1, \ldots, N$ artificial DMUs with input quantities $\widetilde{x}_{i}=x_{i}$ and output quantities $\widetilde{y_{i}}=\left(\hat{\theta}_{i} / \widetilde{\theta}_{i}\right) * y_{i}$.

3.4 Use the $N$ artificial DMUs, generated in Step 3.3, as reference set in a DEA that yields $\hat{\theta}_{i}^{k}$ for each original DMU $i=1, \ldots, N$.

Step 4. For each DMU $i=1, \ldots, N$, calculate a bias corrected efficiency score item $\theta_{i}^{\hat{b} c}$ as $\hat{\theta}_{i}-\left(\frac{1}{K} \sum_{k=1}^{K} \hat{\theta}_{i}^{k}-\hat{\theta}_{i}\right)$.

Step 5. Run a truncated regression (left-truncation at 1 ) of $\theta_{i}^{\hat{b} c}$ on $z_{\mathrm{i}}$ to obtain coefficient estimates $\hat{\beta}$ and an estimate for variance parameter $\hat{\sigma}$ by maximum likelihood.

Step 6. Loop over the following steps 6.1-6.3 $M$ times, in order to obtain a set of $M$ bootstrap estimates $\left(\hat{\hat{\beta}}^{m}, \hat{\hat{\sigma}}^{m}\right)$, with $m=1, \ldots, M$.

6.1 For each DMU $i=1, \ldots, N$, draw an artificial error $\widetilde{\widetilde{\varepsilon}}_{i}$ from the truncated $N(0, \hat{\hat{\sigma}})$ distribution with left-truncation at $1-z_{i} \hat{\hat{\beta}}$.

6.2 Calculate artificial efficiency scores $\widetilde{\tilde{\theta}_{i}}$ as $z_{i} \hat{\hat{\beta}}+\widetilde{\widetilde{\varepsilon_{i}}}$ for each DMU $i=1, \ldots, N$.

6.3 Run a truncated regression (left-truncation at 1 ) of $\widetilde{\widetilde{\theta}}_{i}$ on $z_{i}$ to obtain bootstrap estimates $\hat{\hat{\beta}}^{m}$ and $\hat{\sigma}^{m}$ by maximum likelihood.

Step 7. Calculate confidence intervals and standard errors for $\hat{\beta}$ and $\hat{\sigma}$ from the bootstrap distribution $\hat{\hat{\beta}}^{m}$ and $\hat{\hat{\sigma}}^{m}$.

On the other hand, Shenhar et al. [21] addressed that project efficiency could be assessed by project schedule, budget, and technical goals. They also indicated that efficiency has a largest role in project success and also has an effect on the customers and their satisfaction. Unlike Shenhar et al. [21], Serrador and Turner [22] used key stakeholders' satisfaction for the measure of project success. They studied the relationship between project efficiency and overall project success. They empirically showed that efficiency is important to overall project success. Sundqvist et al. [23] conducted literature review and interviews with Swedish project managers from construction companies on the concepts and effects of efficiency and effectiveness in project-based organizations. They showed that there was no clear differentiation between two terms. However, the results indicated that efficiency and effectiveness would enhance the project performance.

Vitner et al. [24] applied DEA methodology to compare project efficiency in a multi-project environment. According to them, in a multi-project environment, each project is a DMU having its own inputs and outputs. Similarly, in our case, each PMO is a DMU. They suggested three-stage methodology to reduce total number of inputs and outputs to increase DEA's discriminatory power in the case of relatively small number of DMUs. To reduce the number of variables, they used similarity coefficient based on the correlation results. They grouped two variables into one if their correlation is greater than or equals to 0.8 . Fu and $\mathrm{Ou}$ [25] proposed a new measurement method of combining principal component analysis (PCA) and DEA to provide a useful reference for BOE project evaluation and performance improvement, and facilitate a more effective allocation of national energy resources. In prior studies using DEA, the method of integration of DEA with PCA provides more stable results compared to traditional methods since PCA decomposes a number of correlated variables within a given data set into a number of uncorrelated principal components. In our case, we have enough DMUs to meet the DEA rule of thumb. In addition, we observed from the correlation matrix that none of them were high enough 0.8 . Thus, we included all the individual input variables without aggregating these inputs into a fewer number of variables. Swink et al. [26] conducted analyses of relationships 
between new product development (NPD) practices, levels of NPD project efficiency, and market-based project success. To get project efficiency, DEA methodology with multiple dimensions of NPD project performances were used. The DEA model considered development cost and product cost as input resources and product quality and project lead time as outputs. They also proposed and tested the theory of performance tradeoffs in NPD project performance. For the analysis, data was collected by the survey. The measures assessed project variables using a combination of seven-point Likert type scales and ratio scale response formats. In our case, 20 performance measures provide multiple assessment of the five primary roles of PMO suggested by Hill [27].

\subsection{Project Management Office (PMO)}

As corporate requirements for changing the business environment have increased, PMOs have also changed to take on various roles and broader scope. Implementation of a PMO represents it has an official methodology of project management [28]. Thus, the PMO is defined as an organization that standardizes the project management system at the enterprise level, accumulates project experience, provides the necessary knowledge and opportunities for education and training, thereby improving the efficiency of project management [29]. Berry and Parasuraman defined service quality as the ability of the organization [30]. This concept can also be applied to a PMO in terms of project quality. Furthermore, since the quality management can enhance business performance [31], the project quality management by the PMO is getting more important. Also, the organizational change is deemed a trigger event that leads to the organizational development [32], and the awareness for the need for change in management has been raised [33]. In this point of view, the PMO function has a vital role to play in helping organizations adopt and integrate change management with project management [33]. Bates suggested that it could be effective when the scope of the PMO should be extended to changing the organization as well as the assessment of the project risk and performance [28].

Meanwhile, Kwak and Dai also defined that the PMO is an independent organization which has full-time employees, provides and supports administrative and technical services, training and education, and mentoring services [34]. Crawford addressed that PMOs' roles include not only supporting and controlling projects but also establishing project strategy and goals [35]. Besides, Desouza and Evaristo classified the PMO functions into three levels, the strategic, operational, and tactical, in their case study on PMO archetype [36].

On the other hand, Hill [27] categorized the PMO functions into five major domains, practice management, infrastructure management, resource integration, technical support, and business alignment, based on many previous studies, and presented the PMO functions the most specifically and comprehensively.

Although the PMO has provided various definitions for each researcher, it can be seen that the role of the PMO evolves from the management of a single project in a department unit to the management of a whole project portfolio at an enterprise level as a centralized organization. In particular, it aims to improve the contribution of the projects in achieving corporate's business performance rather than to manage the schedule and budget efficient management of a single project.

\section{Methodology}

\subsection{Decision Making Units}

For this research, the on-line survey was conducted from 7 August, 2017 to 30 September, 2017 for PMO managers in Korea as well as PMO expert groups located overseas as shown in Table 1. The 108 respondents responded to the questionnaires for this research. Of the 108 respondents, 90 respondents responded that they were operating an enterprise PMO. The size of the sample we finally used for the further analysis was 87 after averaging the opinions of respondents in the same firm.

32 respondents from South Korea, 16 from the USA, 6 from Brazil, 6 from India, 3 from Spain and so on are shown in Table 1. If you look at the industries to which respondents belong, it is composed 
of IT (31), construction (8), manufacturing (8), consulting (7), finance/banking (7), etc. In terms of years from establishment $(\mathrm{Y})$, it consists of $10.3 \%$ ( $\mathrm{Y} \geq 20 \mathrm{yrs}$ ), $17.2 \%$ (10 yrs. $\leq \mathrm{Y}<20 \mathrm{yrs}$.), $20.7 \%$ (5 yrs. $\leq \mathrm{Y}<10$ yrs.), 11.5\% (4 yrs. $\leq \mathrm{Y}<5$ yrs.), 9.2\% (3 yrs. $\leq \mathrm{Y}<4$ yrs.), 8.0\% (2 yrs. $\leq \mathrm{Y}<3$ yrs.), $10.3 \%$ (1 year $\leq \mathrm{Y}<2$ yrs.), and 12.6\% ( $\mathrm{Y}<1$ year). The profiles of PMOs are shown in Table 1.

Table 1. Profiles of PMO.

\begin{tabular}{|c|c|c|c|}
\hline Division & Category & Frequency & Percent (\%) \\
\hline \multirow{11}{*}{ Country } & South Korea & 32 & 36.9 \\
\hline & USA & 16 & 18.4 \\
\hline & Brazil & 6 & 6.9 \\
\hline & India & 6 & 6.9 \\
\hline & Spain & 3 & 3.4 \\
\hline & UAE & 3 & 3.4 \\
\hline & Belgium & 2 & 2.3 \\
\hline & Denmark & 2 & 2.3 \\
\hline & Saudi Arabia & 2 & 2.3 \\
\hline & Thailand & 2 & 2.3 \\
\hline & Others & 13 & 14.9 \\
\hline \multirow{8}{*}{ Industry } & IT & 31 & 35.7 \\
\hline & Construction & 8 & 9.2 \\
\hline & Manufacturing & 8 & 9.2 \\
\hline & Consulting & 7 & 8 \\
\hline & Finance/banking & 7 & 8 \\
\hline & Government agency & 6 & 6.9 \\
\hline & Telecommunications & 4 & 4.6 \\
\hline & Others & 16 & 18.4 \\
\hline \multirow{5}{*}{ Name } & $\mathrm{PMO}$ & 65 & 74.7 \\
\hline & Center of Excellence & 4 & 4.6 \\
\hline & Program Office & 4 & 4.6 \\
\hline & Project Support Office & 4 & 4.6 \\
\hline & Others & 16 & 11.5 \\
\hline \multirow{8}{*}{ Y (Years from establishment of PMO) } & $\mathrm{Y}<1$ year & 11 & 12.6 \\
\hline & 1 year $\leq Y<2$ years & 9 & 10.3 \\
\hline & 2 years. $\leq \mathrm{Y}<3$ years. & 7 & 8.1 \\
\hline & 3 years. $\leq \mathrm{Y}<4$ years. & 8 & 9.2 \\
\hline & 4 years. $\leq \mathrm{Y}<5$ years. & 10 & 11.5 \\
\hline & 5 years. $\leq \mathrm{Y}<10$ years. & 18 & 20.7 \\
\hline & 10 years. $\leq Y<20$ years. & 15 & 17.3 \\
\hline & $\mathrm{Y} \geq 20$ years. & 9 & 10.3 \\
\hline
\end{tabular}

\subsection{Selection of Input and Output Factors}

The purpose of this research is to evaluate PMOs' relative efficiency using the DEA. Hill proposed PMO's five major functions comprehensively and collectively [27]. So, we used the five main functions defined by Hill as input factors for the analysis. Meanwhile, the PMO performances, as the output factors, were derived from various literature researches including PMBOK ${ }^{\circledR}$ and PRINCE2 ${ }^{\circledR}$, and the project performances presented by the Standish Group International. They comprise on time, on budget, meeting customers' requirements, quality, and project benefit [37-39]. These input and output factors were measured by executives, portfolio or program managers, PMO managers and so on. To measure PMO performances and the degrees of support from the PMO, a seven-point Likert scale was utilized. The descriptive statistics of inputs and outputs are shown in Table 2. It is common that inputs used in DEA are resources that are consumed to produce outputs. However, as Cooper et al. [40] discussed, qualitative variables such as employee competence can be applied.

In the DEA, the more DMUs are desirable. If the number of DMUs is small, then it is difficult to differentiate them since the efficiency scores of them would probably be the same. To prevent it, 
Cooper et al. suggested that the number of DUMs should be three times larger than the sum of the input and output variables [40]. In this research, the total DMUs are eighty-seven and the sum of input and output factors is eleven. Thus, this condition is satisfied.

Table 2. Descriptive statistics of input and output factors.

\begin{tabular}{cccccc}
\hline Div. & Variables & Min. & Max. & Mean & S.D. \\
\hline \multirow{4}{*}{ Inputs } & Practice management & 2.500 & 7.000 & 5.526 & 1.297 \\
& Infrastructure management & 2.500 & 7.000 & 5.433 & 1.305 \\
& Resource integration & 1.250 & 7.000 & 4.648 & 1.242 \\
& Technical support & 1.250 & 7.000 & 5.152 & 1.454 \\
Outputs & Business alignment & 1.000 & 7.000 & 4.990 & 1.522 \\
\hline
\end{tabular}

\section{Results}

\subsection{Result of the Relative Efficiencies by DEA}

The following Table 3 represents the assessment of the internal consistency and validity of scale. As you can see, each latent variable used for the analysis showed high internal consistency. Convergent validity was assessed by using the average variance extracted (AVE) for each latent variable. The result showed that all of AVEs were higher than the suggested threshold of 0.5 .

Table 3. Cronbach's $\alpha$ and AVEs.

\begin{tabular}{|c|c|c|c|c|c|}
\hline Construct & Item & Factor Loading & Cronbach's $\alpha$ & C.R. & $\operatorname{AVE}(\%)$ \\
\hline \multirow{4}{*}{ PM } & Project management methodology & 0.814 & \multirow{4}{*}{0.840} & \multirow{4}{*}{0.701} & \multirow{4}{*}{0.621} \\
\hline & Project management tools & 0.842 & & & \\
\hline & Standards and metrics & 0.881 & & & \\
\hline & Project knowledge management & 0.580 & & & \\
\hline \multirow{4}{*}{$\mathrm{IM}$} & Project governance & 0.848 & \multirow{4}{*}{0.849} & \multirow{4}{*}{0.729} & \multirow{4}{*}{0.620} \\
\hline & Assessment & 0.860 & & & \\
\hline & Organization and structure & 0.793 & & & \\
\hline & Facilities and equipment support & 0.628 & & & \\
\hline \multirow{4}{*}{ RI } & Resource management & 0.778 & \multirow{4}{*}{0.893} & \multirow{4}{*}{0.704} & \multirow{4}{*}{0.681} \\
\hline & Training and education & 0.756 & & & \\
\hline & Career development & 0.850 & & & \\
\hline & Team development & 0.909 & & & \\
\hline \multirow{4}{*}{ TS } & Mentoring & 0.808 & \multirow{4}{*}{0.846} & \multirow{4}{*}{0.654} & \multirow{4}{*}{0.580} \\
\hline & Planning support & 0.792 & & & \\
\hline & Project auditing & 0.677 & & & \\
\hline & Project recovery & 0.762 & & & \\
\hline \multirow{4}{*}{ BA } & Project portfolio management & 0.589 & \multirow{4}{*}{0.827} & \multirow{4}{*}{0.590} & \multirow{4}{*}{0.553} \\
\hline & Customer relationships & 0.693 & & & \\
\hline & Vendor/contractor relationships & 0.846 & & & \\
\hline & Business performance & 0.818 & & & \\
\hline \multirow{6}{*}{ PP } & Project integration and balance & 0.797 & \multirow{6}{*}{0.938} & \multirow{6}{*}{0.875} & \multirow{6}{*}{0.722} \\
\hline & Requirements fulfillment & 0.829 & & & \\
\hline & On time & 0.806 & & & \\
\hline & On Budget & 0.820 & & & \\
\hline & Satisfactory quality & 0.918 & & & \\
\hline & Project benefit accomplishment & 0.919 & & & \\
\hline
\end{tabular}


Table 3. Cont.

\begin{tabular}{|c|c|c|c|c|c|}
\hline Construct & Item & Factor Loading & Cronbach's $\alpha$ & C.R. & AVE $(\%)$ \\
\hline \multirow{5}{*}{ PPMM } & People & 0.849 & \multirow{5}{*}{0.928} & \multirow{5}{*}{0.885} & \multirow{5}{*}{0.722} \\
\hline & PPM process & 0.896 & & & \\
\hline & Technology & 0.877 & & & \\
\hline & Financial management & 0.810 & & & \\
\hline & Relationship & 0.813 & & & \\
\hline Strategic & Alignment with business goals & 0.890 & \multirow{2}{*}{0.847} & \multirow{2}{*}{0.748} & \multirow{2}{*}{0.737} \\
\hline Alignment & Alignment with business priorities & 0.826 & & & \\
\hline
\end{tabular}

As presented in Table 4, the following correlation matrix is added to check the robustness. Table 3 shows that all input variables are significantly correlated with output variable. Thus, all inputs are used for the analysis.

The PMO efficiencies by the DEA are shown in Tables 5 and A1. The results of the CRS model show that 11 DMUs are efficient, and the other DMUs are inefficient. The average efficiency score of the total DMU is as low as 0.751. From the results of the VRS model, it is found that 26 DMUs are efficient, whereas 51 DMUs are inefficient. The average efficiency of the total DMU in the BCC model is 0.863 . The number of efficient DMUs in the VRS model is twice more than that obtained from the CRS model. These results are used to measure the scale efficiencies of DMUs. A total of 11 DMUs including DMU20, DMU35, DMU41, and DMU42 are fully efficient in the scale. In the scale efficiency, the most inefficient PMO is DMU61. The inefficiency of DMU61 is not caused from technical inefficiency. Rather, the scale inefficiency causes the inefficiency of DMU61. Therefore, it would be suggested to improve inefficiency by increasing outputs while inputs remain the same. Among those inefficient DMUs, DMU40 is found to be the least efficient. To reduce the technical inefficiency, various approaches such as improving the PPM processes and the PPM maturity, realigning the structure of the organization, or strengthening the strategic alignment with the business goals are recommended for these PMOs.

Table 4. Correlation matrix.

\begin{tabular}{|c|c|c|c|c|c|c|}
\hline & $\mathrm{PM}^{1}$ & $\mathrm{IM}^{2}$ & $\mathrm{RI}^{3}$ & TS $^{4}$ & BA $^{5}$ & $\mathrm{PP}^{6}$ \\
\hline PM & 1.000 & & & & & \\
\hline IM & $0.754^{* * *}$ & 1.000 & & & & \\
\hline RI & $0.616^{* * *}$ & $0.714^{* * *}$ & 1.000 & & & \\
\hline TS & $0.677^{* * *}$ & $0.765^{* * *}$ & $0.771^{* * *}$ & 1.000 & & \\
\hline BA & $0.475^{* * *}$ & $0.586^{* * *}$ & $0.674^{* * *}$ & $0.726^{* * *}$ & 1.000 & \\
\hline PP & $0.533^{* * *}$ & $0.658^{* * *}$ & $0.633^{* * *}$ & $0.648^{* * *}$ & $0.627^{* * *}$ & 1.000 \\
\hline
\end{tabular}

Table 5. Efficiency score distribution obtained by DEA.

\begin{tabular}{cccc}
\hline Intervals & TE(CRS) & TE(VRS) & SE \\
\hline$<0.5$ & $3(3.4 \%)$ & $0(0.0 \%)$ & $0(0.0 \%)$ \\
$0.50 \sim 0.60$ & $7(8.0 \%)$ & $3(3.4 \%)$ & $0(0.0 \%)$ \\
$0.60 \sim 0.70$ & $20(23.0 \%)$ & $9(10.3 \%)$ & $3(3.4 \%)$ \\
$0.70 \sim 0.80$ & $26(29.9 \%)$ & $13(14.9 \%)$ & $19(21.8 \%)$ \\
$0.80 \sim 0.90$ & $16(18.4 \%)$ & $23(26.4 \%)$ & $26(29.9 \%)$ \\
$0.90 \sim 1.00$ & $4(4.6 \%)$ & $13(14.9 \%)$ & $25(28.7 \%)$ \\
$>1.00$ & $11(12.6 \%)$ & $26(29.9 \%)$ & $14(16.1 \%)$ \\
\hline Mean & 0.751 & 0.863 & 0.871 \\
Min. & 0.431 & 0.516 & 0.639 \\
Max. & 1.000 & 1.000 & 1.019 \\
S.D. & 0.143 & 0.135 & 0.098 \\
\hline
\end{tabular}




\subsection{Impact Factors on PMO Efficiency}

In general, Tobit regression model can be used when the dependent variable value has only a limited range of value. Since PMO efficiency which is a dependent variable only has values between 0 and 1, Tobit regression model is adopted in this study. In this study, to identify the effects of those factors, Tobit analysis is conducted. The dependent variable is the efficiency score obtained by bootstrapped procedures proposed by Simar and Wilson [20] so that dependent variables and independent variables have a statistical nature.

We analyzed the impact of the strategic business alignment on PMO efficiency. Today's corporate business environment achieves corporate strategic goals through the successful operation of project-like tasks. The PMO's role in managing these projects is therefore to achieve the strategic goals of the company by linking projects and business goals, not just the classic goals of successful project completion within the schedule and on the budget. Furthermore, this role of PMO is becoming more important than anything else. That is, efficiency of the PMO can be influenced by how these projects are aligned with the business objectives of the enterprise. Therefore, the effects of two variables, the degree of linkage with business objectives and the degree of linkage with business priorities, on the PMO efficiency are identified. As a result, it is found that the degree of strategic alignment with business goals and the degree of strategic agreement with business priorities are statistically significant at the significance level of 0.01 as shown in Table 6.

Table 6. Tobit analysis for the impact of strategic business alignment on efficiency.

\begin{tabular}{ccccc}
\hline Variables & Parameters & Std. Error & z-Value & $\operatorname{Pr}(>|\mathbf{z}|)$ \\
\hline Alignment with business goals & $0.090^{* * *}$ & 0.009 & 10.01 & 0.000 \\
Alignment with business priorities & $0.081^{* * *}$ & 0.010 & 8.47 & 0.000 \\
\hline \multicolumn{7}{c}{ Notes: ${ }^{* * *}: p$-value $<0.01}$.
\end{tabular}

Therefore, the efficiencies of PMOs are affected by the strategic alignment of project with business goals and business priorities. At the Global Conference for the Future of PMO in 2012, Gedansky emphasized the strategic alignment in achieving the business goals, such as ROI, cost-cutting, and customer satisfaction [41]. Hill highlighted the need for the strategic PMO as a means to achieve business goals and corporate vision in a five-step competency model for PMO. He also stressed that the strategic PMO must continually change their business around best practices to achieve their business goals [42].

Most of the company's work has been project-like, and the success of these projects has had a major impact on the success of the company. Companies therefore are building PMOs, an enterprise-wide organization, for the integrated management of these projects and the allocation of resources in connection with business goals. However, the performance of these PMOs varies from company to company. One of these causes is known to be the maturity of PPM [7]. Thus, the impact of the PPMM on the PMO efficiency was analyzed, and the results are shown in Table 7. We used Gartner's PPMM to measure companies' program and portfolio management maturity. It consists of five dimensions: people, PPM process, technology, financial management, and relationship. Among them, the maturities of people, PPM process, and technology are statistically significant at significance levels of $0.01,0.05$, and 0.1 , respectively. Especially, people are one of the most critical factors of any project-centric endeavor [43]. The people maturity is associated with the interdependency among people with respect to their availability, skills, contribution to projects, and career aspirations. As a result, high maturity can lead to high productivity, efficiency, and performance. The PPM processes turned out to be the next important factor. This means that even if people are the most important factor, efficiency can be improved through the establishment of a systematic process, rather than relying solely on individual ability. Technology is also found to significant factor. This is because the requirements for technology are changed as the PPM processes are changed according to the levels of maturity [43]. 
Table 7. Tobit analysis for the impact of PPMM on efficiency.

\begin{tabular}{ccccc}
\hline Variables & Parameters & Std. Error & $\mathbf{z}$-Value & $\operatorname{Pr}(>|\mathbf{z}|)$ \\
\hline People & $0.126^{* * *}$ & 0.010 & 12.460 & 0.000 \\
Program portfolio management process & $0.123^{* * *}$ & 0.010 & 14.660 & 0.000 \\
Technology & $0.118^{* * *}$ & 0.010 & 14.230 & 0.000 \\
Financial management & 0.004 & 0.015 & 0.239 & 0.811 \\
Relationship & 0.024 & 0.016 & 1.507 & 0.132 \\
\hline \multicolumn{2}{c}{ Notes: ${ }^{* * *}: p$-value $<0.01}$.
\end{tabular}

Notes: ${ }^{* * *}: p$-value $<0.01$.

On the other hand, the financial management maturity and relationship maturity are not statistically significant. The key area of financial management includes how to track costs, forecasts and budgets on project and program basis. Therefore, these key areas are not directly related with the efficiency of PMO. The relationship includes offering appropriate guidance in identifying people who need help and whose help is needed to achieve the desired outcome and this does not have a direct effect on the efficiency.

\subsection{Relationships among Benefit Achievement, Project Benefit Management, and PMO Efficiency}

Project benefits management (PBM) is a structured approach for maximizing business outcomes for an organization [44]. The roles of PBM include the initiating, planning, organizing, executing, controlling of projects, and transitioning and supporting of change in the organization. Its consequences are to achieve predefined project benefits [45], and the project benefit should be managed even after project closing [38]. Since companies' strategic goals are accomplished through the achievement of the target benefits, the benefit management is very important [46]. If the benefit management does not work well and properly, the target benefits cannot be achieved. Besides, highly efficient PMOs may have a greater improvement than low-efficiency PMOs when PBM levels are improved. Thus, the moderating effect of the efficiency on the relationship between benefit achievement and level of project benefit management was analyzed. For this analysis, the level of benefit management of companies was classified into high $(\mathrm{H})$ and low $(\mathrm{L})$ based on the mean value of the degree of project benefit management of companies surveyed. Also, the efficiency score obtained by SFA was divided into two groups of high $(\mathrm{H})$ and low $(\mathrm{L})$. As shown in Figure 1., the high-efficiency group has higher benefit regardless of the level of project benefit management. This means that even though the project benefit management level of the low-efficiency group is higher than that of the high-efficiency group, the performance of the low-efficiency group is lower than that of the high-efficiency group. This therefore indicates that efficiency is more important than project benefit management. This result is consistent with Itumo's finding that the efficiency significantly and positively affects corporate performance [47]. However, there seems to be little moderating effect of efficiency on the relationship between benefit achievement and level of project benefit management. That is, as the level of benefit management improves, the benefit achievement of the group with lower efficiency is also increased as much as the benefit achievement of the group with higher efficiency is improved. Therefore, when we try to improve the level of project benefit management, we can see that the improvement effect is the same regardless of which group is selected, whether it is a high efficiency group or a low efficiency group. 


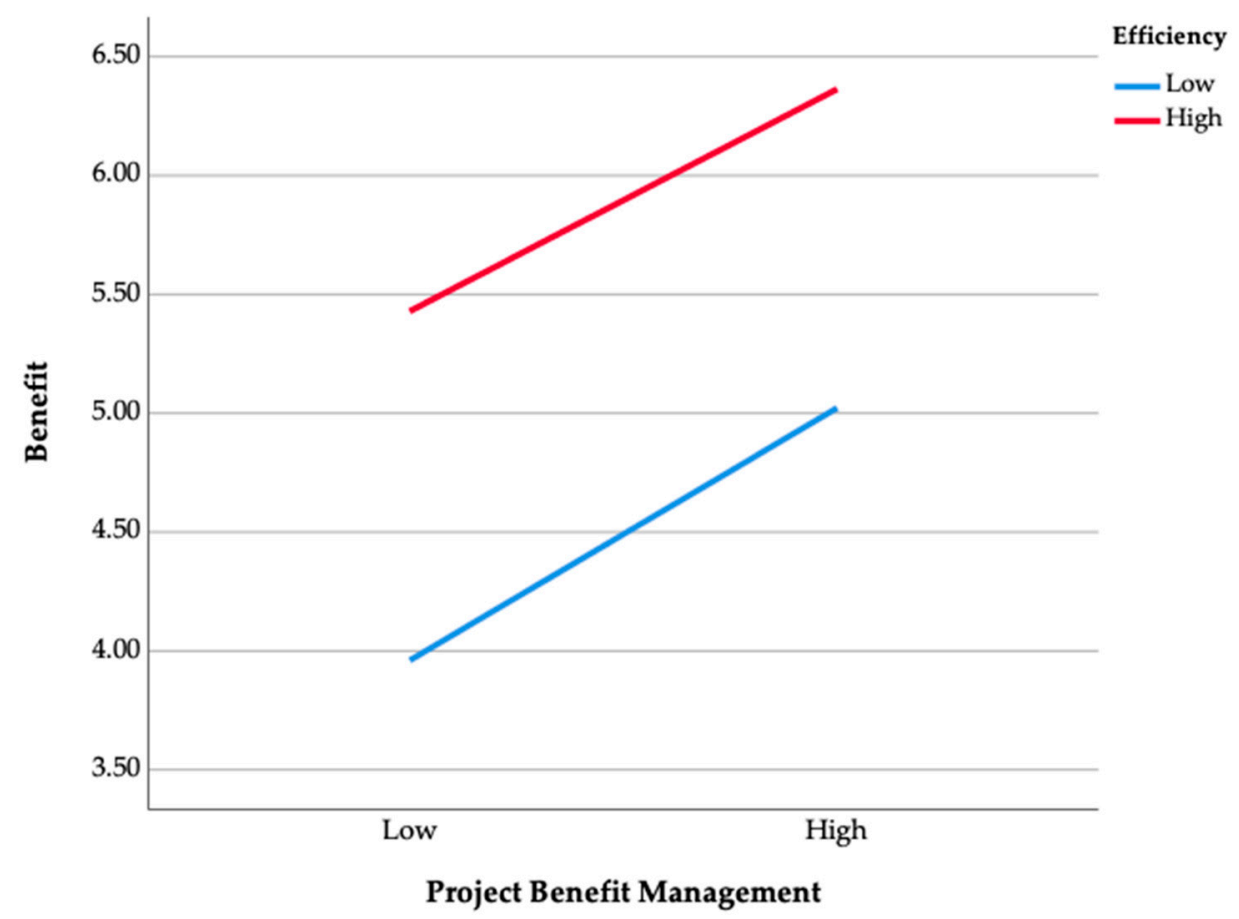

Figure 1. The effects of efficiency on benefit depending on project benefit management.

\section{Conclusions}

The results and implications of this research are summarized as follows. In the case of the CCR model, the average efficiency for the total DMU is 0.75 and the number of efficient DMUs is 11 which accounts for $12.6 \%$ of the total. Therefore, in terms of efficiency, many PMOs' performances are not satisfactory and need improvement. Moreover, the inefficiency of PMO is mostly caused by the scale inefficiency rather than by the technical inefficiency. Thus, to be more efficient, there is a need to maintain the appropriate scale of the input factors.

To identify the effect of the maturity of the PPM, Tobit analysis was conducted. In this research, we used Gartner's PPMM to measure companies' program and portfolio management maturity. It consists of five interdependent core dimensions: people, PPM process, technology, financial management, and relationship. The results showed that maturity of the people, PPM process, and technology were statistically significant. The maturity of people has found to be the most critical component for the efficiency. This implies that in terms of efficiency, workforce assets are one of the most important factors, and their skills, availability, and career aspiration are important components. the availability of people, skills of people, had statistically significant effect on the efficiency of PMO. Therefore, this means that to improve the efficiency, the investment should be made to improve their skills, increase their availability, and enhance their enthusiasm. The PPM processes also appeared to be critical. This implies that it is also important to have systematic procedures to ensure that people's skills and passions are efficiently reflected in performance. To improve the maturity of PPM process, OPM $3^{\circledR}$ of the Project Management Institute (PMI) and P3M3 $3^{\circledR}$ of the Office of Government Commerce (OGC) might be helpful $[48,49]$. For example, OPM ${ }^{\circledR}$ focuses on overall corporate strategy efficiency and integrates project, program, and portfolio management. It provides a method for organizations to understand their Organizational Project Management processes and practices, and to make these processes capable of performing successfully, consistently, and predictably [48]. Technology is found to be another significant factor. Technology is especially necessary for adhering to or using systematic procedures, and as the business environment changes, appropriate technologies for the environment can be provided so that the excellence of the people or procedures can be demonstrated [43].

On the other hand, the maturities of the financial management and relationship were not statistically significant. The main function of financial management includes budget planning, 
budgeting, and budget tracking for project and program portfolios. Therefore, the main function of finance management seems to be weakly related to the efficiency improvement of PMO performance. Based on the role of this relationship, it seems reasonable that it is not directly related to the efficiency of PMO performance $[50,51]$.

The impact of the strategic business alignment on PMO efficiency was also studied. Today's competitive business environment requires the successful execution of project-like tasks to achieve corporate's strategic goals. Thus, the PMO's critical role in managing these projects or portfolio is therefore to align these projects with the business goals. The result showed that the efficiency of the PMO were influenced by this alignment of projects to the business goals. That is, the effects of two components, the degree of linkage between projects and business objectives and the degree of linkage between projects and business priorities, on the PMO efficiency were revealed. These results are in line with the Gedansky's address that the project portfolio should be aligned to the strategic goals to achieve the business goals [41]. Hill [27] also highlighted the need for the PMO as a means to achieve business goals and corporate vision [52,53].

Since project portfolio is linked with corporate's strategic goals, the project benefit management is also very important [46]. Furthermore, more efficient PMOs might have a greater improvement than less efficient PMOs when the level of PBM is increased. The moderating effect of the efficiency on the relationship between benefit achievement and PBM level was therefore analyzed. The result represented that the highly efficient group showed higher benefit achievement regardless of the PBM level. This implies that although the PBM level of the less efficient group is higher than that of the highly efficient group, the benefit achievement of the less efficient group is lower than that of the highly efficient group. This therefore implies that efficiency plays a larger role than PBM in achieving the benefit. This finding supports Itumo's result that the efficiency have significant effect on the corporate performance [47]. However, it is found that there seems to be little moderating effect of efficiency on the relationship between them. This also implies that the same amount of the improvement can be expected regardless of the efficiency level.

As limitations of the study, we could not analyze the efficiency differences by industries because the size difference between samples for each industry was large. In addition, Table 4 shows that some variables have high correlations. In this case, DEA results may be biased. As for future research, the efficiency and characteristics of project management organizations operating in various industrial fields need to be studied and examined from various perspectives. Furthermore, the identification of some other factors affecting the performance of the project management organization should be also tackled. Finally, practical and meaningful results can be obtained through future studies that consider various internal and external environmental variables that may affect the efficiency of the project management organization.

Author Contributions: J.K and D.K conceived and designed the experiments; J.K performed the survey for the experiments and analyzed the data; J.K and D.K wrote the paper.

Funding: This research received no external funding.

Conflicts of Interest: The authors declare no conflict of interest.

\section{Appendix A}

Table A1. Efficiency estimation by DEA.

\begin{tabular}{|c|c|c|c|c|c|c|c|}
\hline \multirow{2}{*}{ DMU } & \multirow{2}{*}{ TE(CRS) } & \multirow{2}{*}{ TE(VRS) } & \multirow{2}{*}{ SE } & \multicolumn{2}{|c|}{$\mathrm{COI}^{1}$} & \multirow{2}{*}{$\Sigma \approx$} & \multirow{2}{*}{ RTS } \\
\hline & & & & PTE & SE & & \\
\hline DMU1 & 0.768 & 0.816 & 0.941 & • & & 1.18 & DRS \\
\hline DMU2 & 0.845 & 0.954 & 0.886 & & - & 1.37 & DRS \\
\hline DMU3 & 0.479 & 0.657 & 0.729 & • & & 2.31 & DRS \\
\hline DMU4 & 0.616 & 0.857 & 0.719 & & - & 2.14 & DRS \\
\hline
\end{tabular}


Table A1. Cont.

\begin{tabular}{|c|c|c|c|c|c|c|c|}
\hline \multirow{2}{*}{ DMU } & \multirow{2}{*}{ TE(CRS) } & \multirow{2}{*}{ TE(VRS) } & \multirow{2}{*}{ SE } & \multicolumn{2}{|c|}{$\mathrm{COI}^{1}$} & \multirow{2}{*}{$\Sigma \approx$} & \multirow{2}{*}{ RTS } \\
\hline & & & & PTE & SE & & \\
\hline DMU5 & 0.659 & 0.863 & 0.764 & & - & 2.24 & DRS \\
\hline DMU6 & 0.770 & 0.816 & 0.944 & $\bullet$ & & 1.42 & DRS \\
\hline DMU7 & 0.531 & 0.603 & 0.881 & - & & 1.87 & DRS \\
\hline DMU8 & 0.770 & 0.853 & 0.903 & - & & 1.75 & DRS \\
\hline DMU9 & 0.500 & 0.552 & 0.906 & - & & 1.81 & DRS \\
\hline DMU10 & 0.655 & 0.829 & 0.790 & & - & 2.39 & DRS \\
\hline DMU11 & 0.801 & 0.810 & 0.988 & $\bullet$ & & 0.89 & IRS \\
\hline DMU12 & 0.845 & 0.985 & 0.858 & & - & 2.25 & DRS \\
\hline DMU13 & 0.703 & 0.943 & 0.746 & & • & 1.87 & DRS \\
\hline DMU14 & 0.588 & 0.671 & 0.876 & - & & 1.15 & DRS \\
\hline DMU15 & 0.677 & 0.830 & 0.816 & & $\bullet$ & 2.18 & DRS \\
\hline DMU16 & 0.774 & 0.826 & 0.937 & - & & 0.92 & IRS \\
\hline DMU17 & 0.629 & 0.711 & 0.885 & $\bullet$ & & 1.93 & DRS \\
\hline DMU18 & 0.764 & 0.752 & 1.016 & - & & 1.24 & DRS \\
\hline DMU19 & 0.867 & 0.907 & 0.956 & $\bullet$ & & 1.36 & DRS \\
\hline DMU20 & 1.000 & 1.000 & 1.000 & & & 1.00 & CRS \\
\hline DMU21 & 0.658 & 0.741 & 0.888 & - & & 1.9 & DRS \\
\hline DMU22 & 0.431 & 0.571 & 0.755 & - & & 2.06 & DRS \\
\hline DMU23 & 0.623 & 0.753 & 0.827 & $\bullet$ & & 1.29 & DRS \\
\hline DMU24 & 0.726 & 0.782 & 0.929 & - & & 1.72 & DRS \\
\hline DMU25 & 0.714 & 0.883 & 0.809 & & - & 2.15 & DRS \\
\hline DMU26 & 0.655 & 1.000 & 0.655 & & $\bullet$ & 0.94 & IRS \\
\hline DMU27 & 0.942 & 0.966 & 0.975 & - & & 1.1 & DRS \\
\hline DMU28 & 0.769 & 0.768 & 1.001 & - & & 0.93 & IRS \\
\hline DMU29 & 0.781 & 0.788 & 0.991 & - & & 1.16 & DRS \\
\hline DMU30 & 0.861 & 0.913 & 0.943 & - & & 1.38 & DRS \\
\hline DMU31 & 0.599 & 0.829 & 0.723 & & - & 2.14 & DRS \\
\hline DMU32 & 0.797 & 0.821 & 0.972 & - & & 1.61 & DRS \\
\hline DMU33 & 0.600 & 0.687 & 0.873 & - & & 2.09 & DRS \\
\hline DMU34 & 0.841 & 0.986 & 0.853 & & - & 1.42 & DRS \\
\hline DMU35 & 1.000 & 1.000 & 1.000 & & & 1.00 & CRS \\
\hline DMU36 & 0.812 & 1.000 & 0.812 & & $\bullet$ & 1.9 & DRS \\
\hline DMU37 & 0.651 & 0.67 & 0.972 & $\bullet$ & & 1.77 & DRS \\
\hline DMU38 & 0.886 & 0.951 & 0.932 & & • & 1.21 & DRS \\
\hline DMU39 & 0.901 & 1.000 & 0.901 & & $\bullet$ & 1.75 & DRS \\
\hline DMU40 & 0.436 & 0.516 & 0.846 & - & & 1.83 & DRS \\
\hline DMU41 & 1.000 & 1.000 & 1.000 & & & 1.00 & CRS \\
\hline DMU42 & 1.000 & 1.000 & 1.000 & & & 1.00 & CRS \\
\hline DMU43 & 0.729 & 0.864 & 0.844 & & • & 1.85 & DRS \\
\hline DMU44 & 0.542 & 0.661 & 0.819 & $\bullet$ & & 2.1 & DRS \\
\hline DMU45 & 0.643 & 0.828 & 0.776 & & $\bullet$ & 1.8 & DRS \\
\hline DMU46 & 0.632 & 0.731 & 0.865 & $\bullet$ & & 1.75 & DRS \\
\hline DMU47 & 0.761 & 0.868 & 0.878 & - & & 1.75 & DRS \\
\hline DMU48 & 0.899 & 1.000 & 0.899 & & - & 1.77 & DRS \\
\hline DMU49 & 1.000 & 1.000 & 1.000 & & & 1.00 & CRS \\
\hline DMU50 & 1.000 & 1.000 & 1.000 & & & 1.00 & CRS \\
\hline DMU51 & 0.823 & 0.992 & 0.829 & & • & 1.44 & DRS \\
\hline DMU52 & 0.702 & 0.738 & 0.952 & - & & 0.8 & IRS \\
\hline DMU53 & 0.694 & 0.893 & 0.777 & & $\bullet$ & 2.27 & DRS \\
\hline DMU54 & 1.000 & 1.000 & 1.000 & & & 1.00 & CRS \\
\hline DMU55 & 1.000 & 1.000 & 1.000 & & & 1.00 & CRS \\
\hline DMU56 & 0.920 & 1.000 & 0.920 & & • & 1.39 & DRS \\
\hline DMU57 & 0.716 & 0.703 & 1.019 & $\bullet$ & & 1.24 & DRS \\
\hline DMU58 & 0.518 & 0.609 & 0.851 & $\bullet$ & & 1.13 & DRS \\
\hline DMU59 & 0.656 & 0.718 & 0.914 & $\bullet$ & & 2.12 & DRS \\
\hline DMU60 & 0.801 & 0.848 & 0.945 & $\bullet$ & & 1.38 & DRS \\
\hline DMU61 & 0.639 & 1.000 & 0.639 & & - & 0.78 & IRS \\
\hline DMU62 & 0.793 & 0.880 & 0.901 & $\bullet$ & & 1.88 & DRS \\
\hline
\end{tabular}


Table A1. Cont.

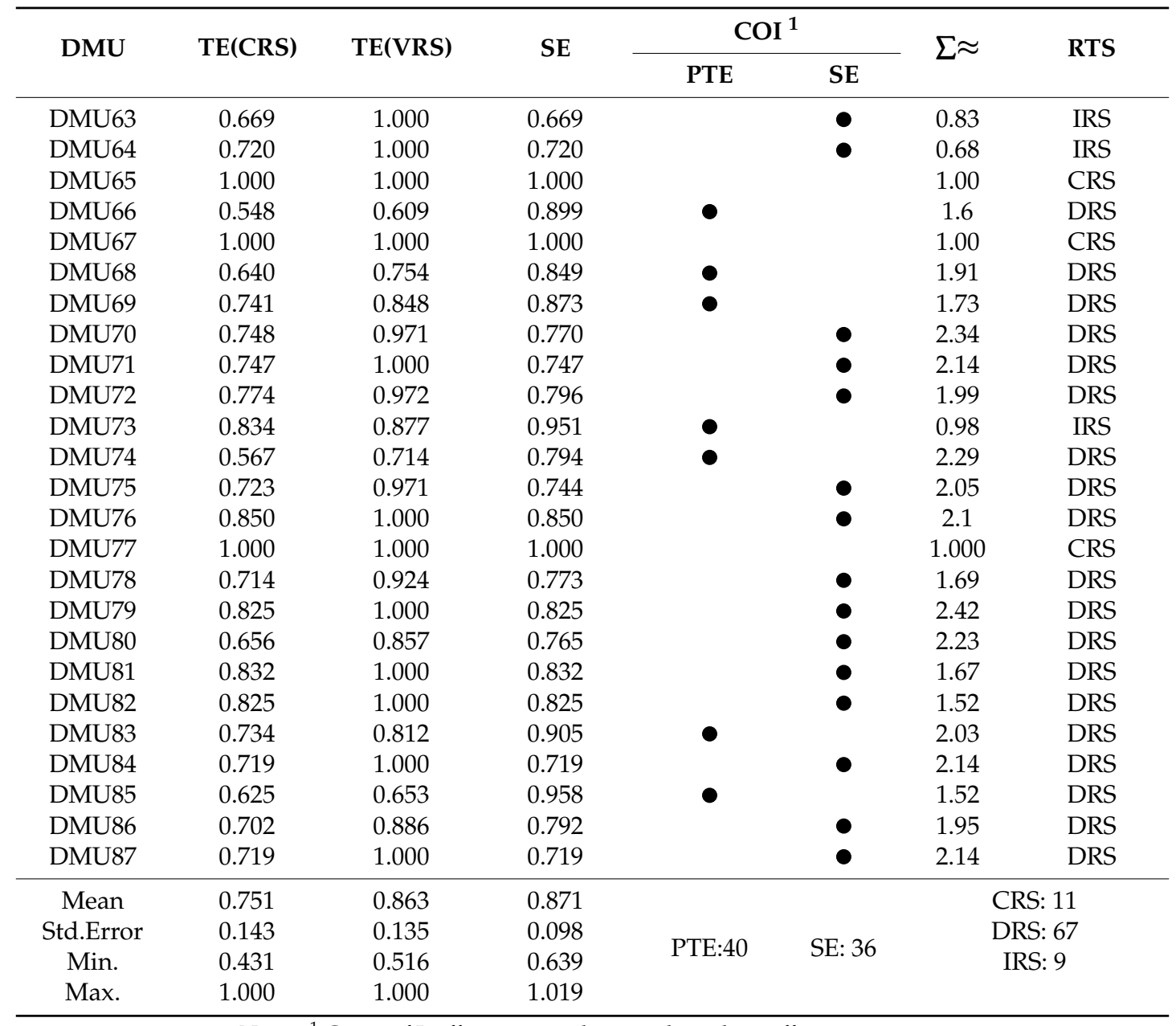

Notes: ${ }^{1}$ Cause of Inefficiency; $\bullet$ indicates where the inefficiency occurs.

\section{References}

1. Project Management vs. Program Management vs. Portfolio Management. Available online: https: / www.planview.com/resources/articles/project-management-vs-program-managementvs-portfolio-management (accessed on 21 October 2018).

2. PM Solutions. The State of the PMO (PMO) 2016: Enabling Strategy Execution Excellence; PM Solutions: Gren Mills, PA, USA, 2016.

3. Park, H.S. Technology convergence, open innovation, and dynamic economy. J. Open Innov. Technol. Mark. Complex. 2017, 3, 1-13. [CrossRef]

4. Ko, K.; Chang, M.; Bae, E.; Kim, D. Efficiency Analysis of Retail Chain Stores in Korea. Sustainability 2017, 9 , 1629. [CrossRef]

5. $\quad$ Peters, T.J. Liberation Management: Necessary Disorganization for the Nanosecond Nineties; Random House Publishing Group: New York, NY, USA, 1994.

6. $\quad$ PMI. A Guide to The Project Management Body of Knowledge (PMBOK Guides); Project Management Institute: Newtown Square, PA, USA, 2013.

7. Kim, S.C.; Yoon, W.H. Analyzing the relationships between project management capability and project performance. Korean Assoc. Logos Manag. 2015, 13, 139-162.

8. Miklosik, A. Improving project management performance through capability maturity measurement. Procedia Econ. Financ. 2015, 30, 522-530. [CrossRef]

9. ITScore Overview for Program and Portfolio Management. Available online: https://www.gartner.com/ doc/3785265/itscore-overview-program-portfolio-management (accessed on 21 October 2018). 
10. PMI. The Impact of PMOs on Strategy Implementation; Project Management Institute: Newtown Square, PA, USA, 2013.

11. How to Align Projects Management with Your Business Strategy. Available online: https: / / www.cio.com/article/2862078/project-management/how-to-align-projects-management-withyour-business-strategy.html (accessed on 21 October 2018).

12. Charnes, A.; Cooper, W.W.; Rhodes, E. Measuring the efficiency of decision making units. Eur. J. Oper. Res. 1978, 2, 429-444. [CrossRef]

13. Han, D.Y.; Kim, S.A. Analysing the Managerial Efficiency of Software Companies by DEA. Prod. Rev. 2008, 22, 5-22.

14. Ko, K.; Kim, D. The Analyses of the Operational Efficiency and Efficiency Factors of Retail Stores Using DEA Model. J. Korean Oper. Res. Manag. Sci. Soc. 2014, 31, 135-150.

15. Park, J.; Yoo, I. A Study on Factors Affecting the Management Efficiency of Korean Pharmaceutical Firms Listed in the KRX-Using DEA and Tobit Model. Prod. Rev. 2013, 27, 137-165.

16. Ko, J.H.; Park, S.H.; Kim, D.C. Efficiency analysis of PMOs for large-scale Information System Projects: Insights for Construction Mega-projects. Construct. Econ. Build. 2015, 15, 34-47. [CrossRef]

17. Banker, R.D.; Charnes, A.; Cooper, W.W. Some models for estimating technical and scale inefficiencies in data envelopment analysis. Manag. Sci. 1984, 30, 1078-1092. [CrossRef]

18. Ju, H.J.; Kim, D.C. Efficiency Analysis of Regional SW Growth Supporting Projects Executing Agencies Using DEA. J. Korean Prod. Oper. Manag. Soc. 2014, 25, 443-463.

19. Lee, J.D.; Oh, D.H. Theory of Efficiency Analysis; Jiphil Media: Seoul, Korea, 2012.

20. Simar, L.; Wilson, P.W. Estimation and inference in two-stage, semi-parametric models of production process. J. Econ. 2007, 136, 31-64. [CrossRef]

21. Shenhar, A.J.; Levy, O.; Dvir, D. Mapping the dimensions of project success. Project Manag. J. 1997, 28 , 5-9.

22. Serrador, P.; Turner, R. The Relationship between Project Success and Project Efficiency. Project Manag. J. 2015, 46, 30-39. [CrossRef]

23. Sundqvist, E.; Backlund, F.; Chronéer, D. What is Project Efficiency and Effectiveness? Procedia Soc. Behav. Sci. 2014, 119, 278-287. [CrossRef]

24. Vitner, G.; Rozenes, S.; Spraggett, S. Using data envelope analysis to compare project efficiency in a multi-project environment. Int. J. Project Manag. 2004, 24, 323-329. [CrossRef]

25. Fu, H.P.; Ou, J.R. Combining PCA with DEA to Improve the Evaluation of Project Performance Data: A Taiwanese Bureau of Energy Case Study. Project Manag. J. 2013, 44, 94-106. [CrossRef]

26. Swink, M.; Talluri, S.; Pandejpong, T. Faster, better, cheaper: A study of NPD project efficiency and performance tradeoffs. J. Oper. Manag. 2006, 24, 542-562. [CrossRef]

27. Hill, G.M. The Complete PMO Handbook; Auerbach Publications: New York, NY, USA, 2004; ISBN 978-1-4200-4682-3.

28. Bates, W.S. Improving project management: Better project management begins with a PMO. IIE Solut. 1998, $30,42-44$.

29. Dinsmore, P.C. Winning in Business with Enterprise Project Management; AMA Publications: New York, NY, USA, 1999.

30. Berry, L.L.; Parasuraman, A. Marketing Services: Competing through Quality; Simon and Schuster: New York, NY, USA, 2004.

31. Kim, J.H.; Jung, S.H. Study on CEO characteristics for management of public art performance centers. J. Open Innov. Technol. Mark. Complex. 2015, 1, 1-21. [CrossRef]

32. Rosha, A.; Lace, N. The scope of coaching in the context of organizational change. J. Open Innov. Technol. Mark. Complex. 2016, 2, 1-14. [CrossRef]

33. Sidhu, R. The PMO Role in Change Management. In Proceedings of the PMO Conference 2015, London, UK, 11 June 2015.

34. Kwak, Y.H.; Dai, C.X. Assessing the value of PMOs (PMO). In Proceedings of the PMI®Research Conference 2000, Paris, France, 21-24 June 2000.

35. Crawford, L. Developing organizational project management capability: Theory and practice. Proj. Manag. J. 2006, 37, 74-86. [CrossRef]

36. Desouza, K.C.; Evaristo, J.R. PMOs: A case of knowledge-based archetypes. Int. J. Inf. Manag. 2006, 26, 414-423. [CrossRef] 
37. Chou, J.S.; Yang, J.G. Project management knowledge and effects on construction project outcomes: An empirical study. Proj. Manag. J. 2012, 43, 47-67. [CrossRef]

38. OGC. Managing Successful Projects with PRINCE2; The Stationery Office: Norwich, UK, 2009.

39. Yeung, J.F.; Chan, A.P.; Chan, D.W. Developing a performance index for relationship-based construction projects in Australia: Delphi study. J. Manag. Eng. 2009, 25, 59-68. [CrossRef]

40. Cooper, W.W.; Seiford, L.M.; Zhu, J. Handbook on Data Envelopment Analysis; Springer Science \& Business Media: New York, NY, USA, 2011.

41. Gedansky, L. Strategic PMO. In Proceedings of the Global Conference for the Future of PMO, Seoul, Korea, 5 July 2012.

42. Hill, G.M. Evolving the PMO: A Competency Continuum. Inf. Syst. Manag. 2004, 21, 45-51. [CrossRef]

43. Mieritz, L.; Fitzgerald, D.; Gomolski, B.; Light, M. Toolkit Best Practices: Program and Portfolio Management Maturity Model; Gartner: stamford, CT, USA, 2007.

44. Introduction to Benefits Management for Programmes and Projects. Available online: https://www.financeni.gov.uk/articles/programme-and-project-benefits-management (accessed on 11 November 2018).

45. Benefits Realisation Management. Available online: https://en.wikipedia.org/wiki/Benefits_realisation_ management (accessed on 11 November 2018).

46. Sopko, J.A.; Demaria, A. Benefits management: How Siemens focuses on benefits to accelerate value delivery. In Proceedings of the PMI ${ }^{\circledR}$ Global Congress 2013, New Orleans, LO, USA, 27-29 October 2013.

47. Itumo, N.P. Relationship between Efficiency and Financial Performance of Commercial Banks in Kenya. Master's Thesis, University of Nairobi, Nairobi, Kenya, 2012.

48. OPM3. Available online: https://en.wikipedia.org/wiki/OPM3 (accessed on 11 November 2018).

49. PMI. Organizational Project Management Maturity Model; Project Management Institute: Campus Boulevard Newtown Square, PA, USA, 2003.

50. Yun, J.H. How do we conquer the growth limits of capitalism? Schumpeterian Dynamics of Open Innovation. J. Open Innov. Technol. Mark. Complex. 2015, 1, 17. [CrossRef]

51. Gupta, A.; Dey, A.; Singh, G. Commenting corporations and communities: towards a theory of social inclusive open innovation. J. Open Innov. Technol. Mark. Complex. 2017, 3, 17. [CrossRef]

52. Cooke, P. Complex spaces: global innovation networks \& territorial innovation systems in FI formation \& communication technologies. J. Open Innov. Technol. Mark. Complex. 2017, 3, 9.

53. Yun, J.; Won, D.; Park, K. Dynamics from open innovation to evolutionary change. JOItmC 2016, 2, 1-22. [CrossRef] 